\title{
Influenza-associated hospitalisations in Finland from 1996 to 2010: unexpected age-specific burden during the influenza A(H1N1)pdm09 pandemic from 2009 to 2010
}

A Jacks (andreas.jacks@ki.se)1,2, J Ollgren³, T Ziegler4, 0 Lyytikäinen (outi.lyytikainen@thl.fi)2

1. European Programme for Intervention Epidemiology Training (EPIET), European Centre for Disease Prevention and Control, Stockholm, Sweden

2. Epidemiologic Surveillance and Response Unit, Department of Infectious Disease Surveillance and Control, National Institute for Health and Welfare (THL), Helsinki, Finland

3. Vaccination Programme Unit, Department of Vaccination and Immune Protection, National Institute for Health and Welfare (THL), Helsinki, Finland

4. Viral Infections Unit, Department of Vaccination and Immune Protection, National Institute for Health and Welfare (THL), Helsinki, Finland

Citation style for this article:
Jacks A, Ollgren J, Ziegler T, Lyytikäinen 0. Influenza-associated hospitalisations in Finland from 1996 to 2010 : unexpected age-specific burden during the

influenza A(H1N1)pdmog pandemic from 2009 to 2010 . Euro Surveill, 2012;17(38): pii=20276. Available online: http://www.eurosurveillance.org/ViewArticle. influenza $\mathrm{A}\left(\mathrm{H}_{1} \mathrm{~N} 1\right)$ pdm aspx?Articleld $=20276$

Article submitted on 23 March 2012 / published on 20 September 2012

To assess the burden of influenza on the Finnish healthcare system, we analysed hospitalisations during 1996-2010 using the International Classification of Diseases codes potentially related to influenza and its complications from the national hospital discharge registry. To compare the influenza $A\left(\mathrm{H}_{1} \mathrm{~N}_{1}\right)$ pdmog pandemic with previous influenza seasons in 1996-2009, we calculated hospitalisation rates by age- and diagnostic groups. We built a negative binomial regression model based on times series analysis to assess the impact of the pandemic. Influenza-associated hospitalisation rates were higher during the pandemic compared to pre-pandemic influenza seasons for 5-24 year-olds (incidence rate ratio (IRR): 1.52, 95\% confidence interval (CI): 1.44-1.60) and 25-64 year-olds (IRR: 1.33 , 95\% Cl: 1.29-1.36), but did not differ for persons aged $\geq 65$ years (IRR: $0.98,95 \% \mathrm{Cl}$ : $0.97-$ 1.00). Hospitalisation rates exceeded the upper limit of the prediction line by $177 \%$ in 5-24 year-olds, $66 \%$ in $0-4$ year-olds and $57 \%$ in $25-64$ year-olds. During the influenza season of 2003/04, all age groups had higher-than-expected hospitalisation rates, whereas other seasonal peaks were only notable among persons aged $\geq 65$ years. These age-specific differences in the hospital burden underscore the importance of the continuous surveillance of hospitalisations in order to evaluate immunisation priorities for seasonal influenza and pandemic preparedness including use of antiviral medication.

\section{Introduction}

The impact of the influenza $A\left(\mathrm{H}_{1} \mathrm{~N}_{1}\right)$ pdmog pandemic on relevant public health indicators, such as laboratory-confirmed severe cases, has been widely reported in the European region [1] and also in Finland [2]. However, surveillance based only on laboratory-confirmed cases may underestimate the disease burden due to the low likelihood of testing in some clinical situations and the increased usage of rapid test methods with low sensitivity [3]. The availability of diagnostic tests and testing activity may vary between countries, and thus international comparisons must be done with caution.

Within the European monitoring of excess mortality for public health action [4], pooled results from eight European countries showed higher all-cause mortality in children during the influenza $\mathrm{A}\left(\mathrm{H}_{1} \mathrm{~N}_{1}\right)$ pdmog pandemic in comparison with the three previous years [5] but this finding was not detected in mortality data from the individual countries, including Finland. However, mortality does not reflect the whole burden of disease $[6,7]$.

The impact of seasonal and pandemic influenza on healthcare systems, particularly inpatient care, can be assessed by using a wide range of influenza-associated conditions leading to hospitalisation. In the United States, two retrospective studies have used a list of influenza-associated discharge diagnoses to estimate excess hospitalisations due to influenza during seasonal influenza periods, where a comparison between seasons provided information on important virological factors, such as the dominant influenza virus subtype and vaccine match $[6,8]$. Using a similar methodology, Widgren et al. [9] described the hospital burden of influenza in Denmark during the pandemic and the previous five years and revealed a higher than expected hospitalisation burden in children and young adults aged 5-24 years, but no excess burden in persons aged 65 years and above.

In the present study, we describe observed numbers of influenza-associated hospitalisations in Finland by age 
and influenza-associated diagnostic groups during the influenza $\mathrm{A}\left(\mathrm{H}_{1} \mathrm{~N}_{1}\right)$ pdmog pandemic in comparison with the 13 previous influenza seasons. We also present a prediction model for influenza hospitalisations during the pandemic, incorporating data from the nationwide laboratory-based surveillance of influenza and other seasonally circulating respiratory pathogens.

\section{Methods}

\section{Data sources}

In Finland (population 5.4 million in 2010), the National Hospital Discharge Register (HILMO) receives reports on all discharges from inpatient care providers on an annual basis. Each report includes a national identity code for the patient, the first three diagnoses given to the patient according to the International Classification of Diseases 10th revision (ICD-10) from 1996 and onwards, age, sex and place of residence, admission and discharge dates, name and place of attending hospital, type of service and medical specialty. Thus, the study base from which we obtained the data on hospitalisations consisted of all the discharges reported to HILMO from the entire country for the years 1996-2010. Yearly age-specific population data from Statistics Finland for the years 1996-2010 were used to calculate hospitalisation rates.

We obtained weekly numbers of seasonally circulating respiratory pathogens (influenza $A$ and $B$, parainfluenza, adenovirus and respiratory syncytial viruses (RSV), Mycoplasma pneumoniae, Chlamydia pneumoniae and Bordetella pertussis) from the National Infectious Disease Register, to which all clinical microbiology laboratories electronically notify all positive findings (culture, antigen, serology and polymerase chain reaction (PCR)) for the aforementioned pathogens.

\section{Definitions}

We obtained data on influenza-associated hospitalisations from HILMO according to a list of ICD-10 discharge diagnoses and classified these into five diagnostic groups $[6,8,9]$ : influenza, viral or unspecified pneumonia, bacterial pneumonia, febrile convulsions and acute respiratory distress syndrome (ARDS). A list of ICD-10 codes used with corresponding diagnostic groups is presented in Table 1.

Influenza seasons were defined as starting from week 30 to week 15 of the following year; this extended season was created to accommodate the influenza $A\left(\mathrm{H}_{1} \mathrm{~N}_{1}\right)$ pdmog pandemic for which the onset and peak in influenza activity, as measured through laboratory-based surveillance, came much earlier than in the previous seasons [2,9]. Hospitalisations were analysed according to the following age groups: $0-4,5-24,25-64$ and 65 years and above [9]. In the study database, the national identity code was replaced with a unique surrogate identifier; each individual's influenza-associated hospitalisations reported to HILMO within a sixweek period were counted as one unique episode of influenza-associated hospitalisation [9].

\section{Analyses and statistics}

We calculated age-specific weekly hospitalisation rates per 100,000 population using unique hospitalisation episodes. We compared the hospitalisation rate during the influenza $A\left(\mathrm{H}_{1} \mathrm{~N}_{1}\right)$ pdmog pandemic with the mean hospitalisation rate of pre-pandemic influenza seasons by calculating the age-specific incidence rate ratio (IRR) with a $95 \%$ confidence interval (CI).

We stratified the data on all the influenza-associated hospitalisations by age groups and the previously described five diagnostic groups for each season. We compared the stratum-specific numbers of hospitalisations during the pandemic with the median numbers for pre-pandemic influenza seasons by calculating the risk ratio (RR) with a 95\% confidence interval $(\mathrm{Cl})$ for each age-specific diagnosis group using binomial regression.

Furthermore, we constructed a time series in which weekly age-specific unique hospitalisation episodes were plotted from week 1 of 1996 to week 15 of 2010 . We

\section{TABLE 1}

Diagnostic group classification of International Classification of Diseases 10th revision discharge diagnoses used to identify influenza-associated hospitalisations from the National Hospital Discharge Register, Finland, 1996-2010

\begin{tabular}{|c|c|}
\hline Diagnostic group & International Classification of Diseases, 10 th revision discharge diagnoses \\
\hline Influenza & $\begin{array}{l}\text { G051F, G0510, H671B, J09, Jo91, J091A, J091B, J099, J10, J100, J101, J101A, J101B, J101C, J108, J108A, } \\
\text { J108B, J108C, J11, J110, J111, J111A, J111B, J111C, J118, J118A, J118B, J118C, I411A }\end{array}$ \\
\hline Viral or unspecified pneumonia & $J_{12}, J_{120}, J 121, J 122, J 128, J 129, J 18, J 180, J 181, J 182, J 188, J 189$ \\
\hline Bacterial pneumonia & $\begin{array}{l}\text { J13, J139, J139A, J139B, J14, J149, J149A, J149B, J15, J150, J151, J152, J153, J154, J155, J156, J156A, J157, } \\
\text { J158, J159, J16, J160, J168, J170, J170A, J170B, J170C, J170D, J170E, J170F, J170H, J171, J171A, J171B, J171C, } \\
\text { J171D, J172, J172A, J172B, J172C, J172D, J173, J173A, J173B, J173C, J178, J178A, J178B, J178C }\end{array}$ \\
\hline Febrile convulsions & R560 \\
\hline ARDS & J96, J960, J969 \\
\hline
\end{tabular}

ARDS: acute respiratory distress syndrome. 
Incidence rates for influenza-associated hospitalisations during the influenza A(H1N1)pdm09 pandemic and the prepandemic influenza seasons 1996-2009, Finland

\begin{tabular}{|c|c|c|c|c|c|c|c|c|}
\hline \multicolumn{4}{|c|}{ Influenza $\mathrm{A}\left(\mathrm{H}_{1} \mathrm{~N}_{1}\right)$ pdmog pandemic } & \multicolumn{5}{|c|}{ Pre-pandemic influenza seasons 1996-2009 } \\
\hline $\begin{array}{l}\text { Age group } \\
\text { (years) }\end{array}$ & $\begin{array}{c}\text { Total } \\
\text { number }\end{array}$ & $\begin{array}{c}\text { Incidence } \\
\text { rate }^{a}\end{array}$ & $95 \% \mathrm{Cl}$ & $\begin{array}{c}\text { Mean } \\
\text { number/season }\end{array}$ & $\begin{array}{c}\text { Incidence } \\
\text { rate }^{\mathrm{a}}\end{array}$ & $95 \% \mathrm{Cl}$ & IRR & $95 \% \mathrm{Cl}$ \\
\hline $0-4$ & 1,937 & 16.59 & $14.64-16.47$ & 1,700 & 15.19 & $14 \cdot 99-15 \cdot 39$ & 1.09 & $1.04-1.14$ \\
\hline $5-24$ & 1,725 & 3.54 & $3 \cdot 38-3 \cdot 72$ & 1,144 & 2.33 & $2.30-2.37$ & 1.52 & $1.44-1.60$ \\
\hline $25-64$ & 7,554 & 6.70 & $6.55-6.85$ & 5,460 & 5.05 & $5.02-5.09$ & 1.33 & $1.29-1.36$ \\
\hline$\geq 65$ & 16,717 & 46.48 & $45.78-47.19$ & 14,662 & 47.26 & $47.05-47.47$ & 0.98 & $0.97-1.00$ \\
\hline Total & 27,933 & 13.36 & $13.20-13.52$ & 22,965 & 11.53 & $11.48-11.57$ & 1.16 & $1.15-1.17$ \\
\hline
\end{tabular}

$\mathrm{Cl}$ : confidence interval; IRR: incidence rate ratio.

${ }^{a}$ Hospitalisation episodes per 100,000 of the age group population/week.

predicted age-specific hospitalisation rates during the influenza $A\left(\mathrm{H}_{1} \mathrm{~N}_{1}\right)$ pdmog pandemic by applying a negative binomial regression model to the hospitalisation data from the pre-pandemic influenza seasons. In the model, we included weekly reports of seasonally circulating respiratory pathogens as covariates with a time lag of three weeks as suggested by simulations. We also included a seasonality index by months and longterm periodicity based on the observed periodicity for RSV (two years) and a range of periodicity observed for Mycoplasma pneumoniae (three years, seven years) [10]. Previously observed peaks in seasonal influenza were not removed since we believed that those events are expectable in influenza transmission and dynamics $[6,8,11,12]$. Observed age-specific hospitalisations during the pandemic were compared to the upper bound of the $99 \% \mathrm{Cl}$ of the corresponding age-specific prediction obtained from the model, which we expressed as relative differences (\%) for each age group. All analyses were performed using Stata software version 10.1 (Stata corporation, College Station, TX, USA).

\section{Ethical approval and data protection}

The study protocol was approved by the ethics committee of the National Institute for Health and Welfare (THL), and the appropriate permission to use the data from HILMO, which is administrated by the THL, was acquired through an internal application and review process.

\section{Results}

A total of 535,862 influenza-associated hospitalisations were identified from 1996 to 2010; 440,922 of these were unique hospitalisation episodes.

Based on the analysis of unique hospitalisation episodes, the overall influenza-associated hospitalisation rate was $16 \%$ higher during the influenza $A\left(\mathrm{H}_{1} \mathrm{~N}_{1}\right)$ pdmog pandemic as compared to the mean rate of pre-pandemic influenza seasons (Table 2). The hospitalisation rates differed by age groups: statistically significant excesses were observed in children and adults (age groups 0-4 years, 5-24 years and 25-64 years), whereas no excess was detected in persons aged 65 and above. The magnitude of excess hospitalisation was highest in 5-24 year-olds and 25-64 year-olds.

Based on the analysis of all the hospitalisations, discharge diagnoses of influenza, viral pneumonia and ARDS were more frequent during the pandemic as compared to pre-pandemic seasons, but discharge diagnoses of bacterial pneumonia and febrile convulsions were less frequent (Table 3). When analysing discharge diagnoses by age groups, influenza, viral pneumonia and ARDS remained more common during the pandemic as compared to pre-pandemic seasons in $0-4$ year-olds, and influenza and viral pneumonia remained more common in age groups 5-24 and 25-64 years. In persons aged 65 and above, viral pneumonia and ARDS were more common during the pandemic than during pre-pandemic seasons. The number of hospitalisations with discharge diagnoses corresponding to ARDS during the pandemic was 726 for all age groups, and the median number was 540 in previous seasons (range, 248-760). The diagnoses of bacterial pneumonia and febrile convulsions remained less frequent during the pandemic as compared to the previous seasons in all age groups.

In the time series analyses, the model built on pre-pandemic hospitalisation data and notifications from the laboratory-based surveillance of seasonally circulating respiratory pathogens fitted well with the observed hospitalisation rates during the same period (Figure 1). Very small autocorrelations were left in the residuals, which showed only a minor effect on the prediction and its limits when all covariates were added to the model. A peak in influenza-associated hospitalisations in all four age groups was observed during the influenza season 2003/04. When extending the prediction line to the influenza $A\left(\mathrm{H}_{1} \mathrm{~N}_{1}\right)$ pdmog pandemic, hospitalisation 
TABLE 3

Influenza-associated hospitalisations by age- and diagnostic groups during the influenza A(H1N1)pdm09 pandemic and the pre-pandemic influenza seasons 1996-2009, Finland

\begin{tabular}{|c|c|c|c|c|c|c|}
\hline Age and diagnostic group & $\begin{array}{c}\text { Number of } \\
\text { hospitalisations in } \\
\text { the influenza } \mathrm{A}\left(\mathrm{H}_{1} \mathrm{~N}_{1}\right) \\
\text { pdmog pandemic }\end{array}$ & $\begin{array}{l}\text { Median number of } \\
\text { hospitalisations in the } \\
\text { pre-pandemic influenza } \\
\text { seasons } 1996-2009\end{array}$ & $\begin{array}{l}\text { Range in } \\
\text { influenza } \\
\text { seasons } \\
1996-2009\end{array}$ & Risk ratio ${ }^{a}$ & $95 \% \mathrm{Cl}$ & $p$ \\
\hline \multicolumn{7}{|l|}{ All age groups } \\
\hline Influenza & 1,826 & 580 & $358-1844$ & 1.77 & $1.69-1.86$ & 0.000 \\
\hline $\begin{array}{l}\text { Viral or unspecified } \\
\text { pneumonia }\end{array}$ & 25,372 & 14,937 & $11,607-25,730$ & 1.20 & $1.19-1.21$ & 0.000 \\
\hline Bacterial pneumonia & 6,799 & 9,089 & $7,366-10,811$ & 0.59 & $0.58-0.60$ & 0.000 \\
\hline Febrile convulsions & 392 & 616 & $472-908$ & 0.49 & $0.45-0.55$ & 0.000 \\
\hline ARDS & 726 & 540 & $248-760$ & 1.10 & $1.02-1.19$ & 0.011 \\
\hline \multicolumn{4}{|l|}{$0-4$ years } & 0.90 & $0.86-0.94$ & 0.000 \\
\hline Influenza & 364 & 108 & $54-341$ & 2.53 & $2.28-2.81$ & 0.000 \\
\hline $\begin{array}{l}\text { Viral or unspecified } \\
\text { pneumonia }\end{array}$ & 1,077 & 739 & $517-964$ & 1.27 & $1.22-1.33$ & 0.000 \\
\hline Bacterial pneumonia & 232 & 353 & $264-537$ & 0.55 & $0.48-0.62$ & 0.000 \\
\hline Febrile convulsions & 339 & 506 & $389-779$ & 0.56 & $0.51-0.62$ & 0.000 \\
\hline ARDS & 11 & 4 & $2-12$ & 2.10 & $1.11-3.99$ & 0.023 \\
\hline \multicolumn{4}{|l|}{ 5-24 years } & 1.20 & $1.14-1.25$ & 0.000 \\
\hline Influenza & 428 & 75 & $49-124$ & 3.68 & $3.32-4.08$ & 0.000 \\
\hline $\begin{array}{l}\text { Viral or unspecified } \\
\text { pneumonia }\end{array}$ & 1,035 & 585 & $409-915$ & 1.06 & $1.02-1.11$ & 0.006 \\
\hline Bacterial pneumonia & 398 & 444 & $376-650$ & 0.56 & $0.52-0.62$ & 0.000 \\
\hline Febrile convulsions & 29 & 58 & $40-72$ & 0.34 & $0.23-0.49$ & 0.000 \\
\hline ARDS & 16 & 17 & $11-23$ & 0.64 & $0.39-1.06$ & 0.083 \\
\hline \multicolumn{4}{|l|}{ 25-64 years } & 1.14 & $1.12-1.16$ & 0.000 \\
\hline Influenza & 776 & 118 & $71-363$ & $3 \cdot 37$ & $3.11-3.65$ & 0.000 \\
\hline $\begin{array}{l}\text { Viral or unspecified } \\
\text { pneumonia }\end{array}$ & 6,173 & 3,067 & $2,315-6,069$ & 1.19 & $1.17-1.21$ & 0.000 \\
\hline Bacterial pneumonia & 2,169 & 2,546 & $2,228-3,066$ & 0.59 & $0.57-0.61$ & 0.000 \\
\hline Febrile convulsions & 15 & 22 & $12-48$ & 0.43 & $0.25-0.72$ & 0.001 \\
\hline ARDS & 299 & 217 & $105-320$ & 0.99 & $0.88-1.11$ & 0.814 \\
\hline \multicolumn{4}{|l|}{$\geq 65$ years } & 0.95 & $0.94-0.95$ & 0.000 \\
\hline Influenza & 258 & 322 & $111-1176$ & 0.48 & $0.42-0.54$ & 0.000 \\
\hline $\begin{array}{l}\text { Viral or unspecified } \\
\text { pneumonia }\end{array}$ & 17,087 & 10,766 & $7,936-17,782$ & 1.22 & $1.21-1.23$ & 0.000 \\
\hline Bacterial pneumonia & 4,000 & 5,816 & $4,414-7,121$ & 0.59 & $0.57-0.60$ & 0.000 \\
\hline Febrile convulsions & 9 & 15 & $8-29$ & 0.49 & $0.25-0.96$ & 0.038 \\
\hline ARDS & 400 & 304 & $127-417$ & 1.16 & $1.05-1.28$ & 0.005 \\
\hline
\end{tabular}

ARDS: acute respiratory distress syndrome; $\mathrm{Cl}$ : confidence interval.

a Risk ratio per age- and diagnostic group during pandemic versus previous influenza seasons calculated from the binomial regression model. 
Observed influenza-associated hospitalisation rates by age groups per 100,000 population of the respective age groups per week, Finland, 1996-2010 ( $\mathrm{n}=440,922)$
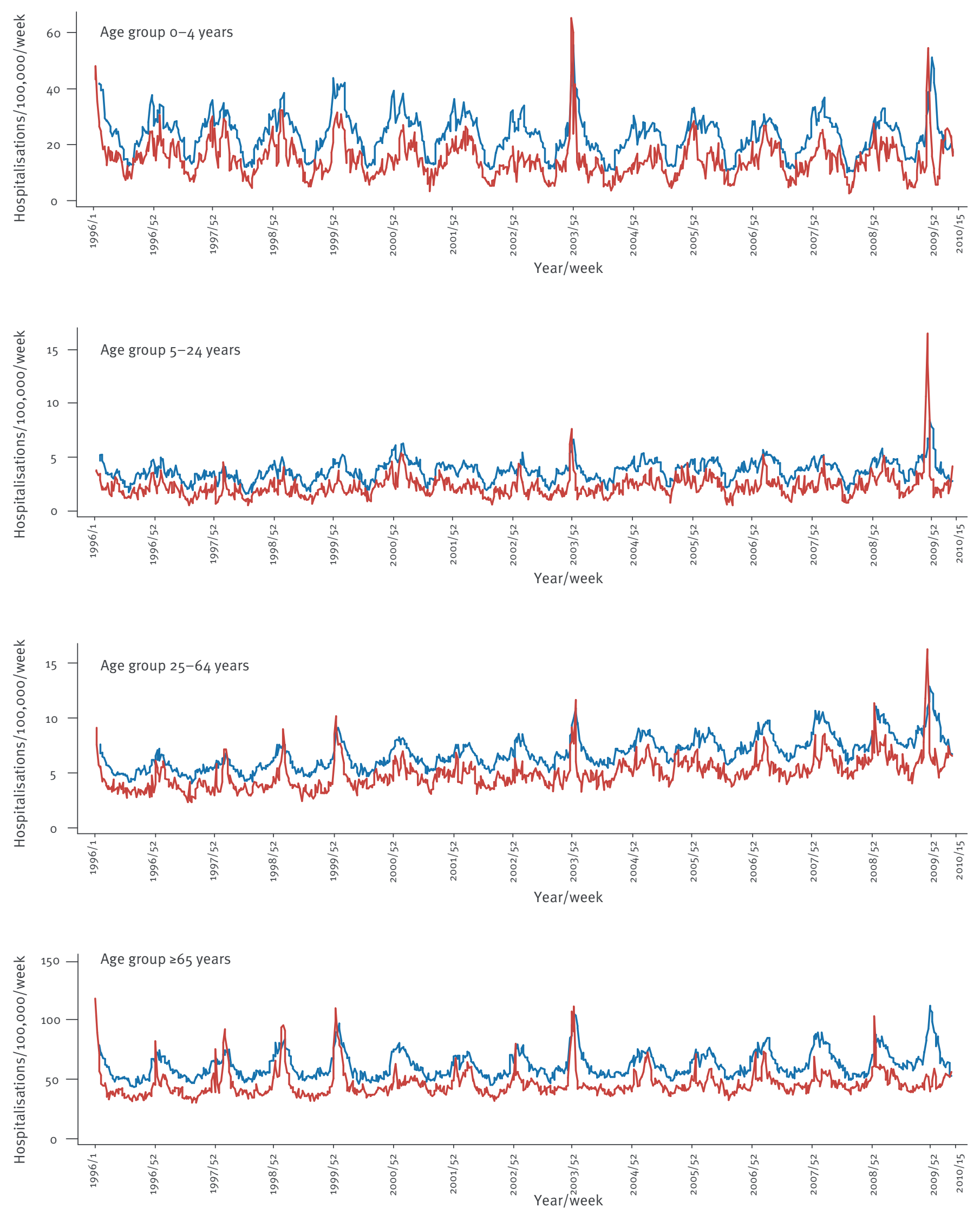

The red line represents the observed influenza-associated hospitalisation rates in Finland by age groups per 100,000 population of the respective age groups per week. The blue line represents the upper limit of the $99 \%$ confidence interval for the prediction line which was obtained from the negative binomial regression model using data from the pre-pandemic influenza seasons. 
rates exceeded the upper bound of the prediction line in the age groups $0-4,5-24$ and $25-64$ years, and the observed peak at week 46 in 2009 occurred earlier than predicted. The time series model predicted a similar peak in influenza-associated hospitalisations for individuals aged 65 and above, but no excess in hospitalisation rate was seen during the pandemic.

The hospitalisation rates varied between age groups (Figure 1 ). In the children aged $0-4$ years, the rate peaked at 50/100,000 population of this respective age group/week during the influenza $\mathrm{A}\left(\mathrm{H}_{1} \mathrm{~N}_{1}\right)$ pdmog pandemic, as compared to $30 / 100,000$ population of the respective age group/week in pre-pandemic peaks. In the age groups 5-24 years and 25-64 years, peak rate during the pandemic reached $15 / 100,000$ population of these respective age groups/week, whereas the seasonal peak rates usually were below $5 / 100,000$ population of these respective age groups/week. In the persons aged 65 and above, the hospitalisation rate during the pandemic did not exceed 50/100,000 population of this respective age group/week, whereas the seasonal peak rates in 1999/00, 2003/04 and 2008/09 were up to $100 / 100,000$ population of the same respective age group/week.

During the peak week of the pandemic (at week 46, 2009), the observed hospitalisation rates exceeded the upper $99 \% \mathrm{Cl}$ of the predicted rates by $177 \%$ in
5-24 year-olds, $66 \%$ in $0-4$ year-olds and $57 \%$ in 25-64 year-olds, but remained below the expected hospitalisation rate in people aged 65 years and above (Figure 2).

\section{Discussion}

Our study showed, based on the national hospital discharge register data, an increase in influenza-associated hospitalisation rates during the influenza $A\left(\mathrm{H}_{1} \mathrm{~N}_{1}\right)$ pdmog pandemic in Finland as compared to the prepandemic seasons 1996-2009. The burden of the pandemic on hospitalisation rates was most pronounced in people aged 5-24 and 25-64 years, whereas there was no difference in persons aged 65 years and above.

The present study was initiated to provide national data on influenza-associated hospitalisations in Finland, using similar methodology as a study from Denmark [9]. As in Denmark, we found a higher than expected hospitalisation burden during the pandemic in persons aged 5-24 years, but the same phenomenon was also detected in persons aged 25-64 years. As shown by the absolute numbers and graphical presentation of the time series, there was no increase in the burden of hospitalisation in persons aged 65 years and above, which was also noted in Denmark. This is partly explained by the presence of cross-reacting antibodies against the Spanish influenza of 1918 or descendants

\section{FIGURE 2}

Relative difference between observed influenza-associated hospitalisations by age groups during the influenza A(H1N1) pdm09 pandemic and the upper limit of the $99 \%$ confidence interval for the prediction line based on pre-pandemic hospitalisation data, Finland, 1 January 2009-18 April 2010

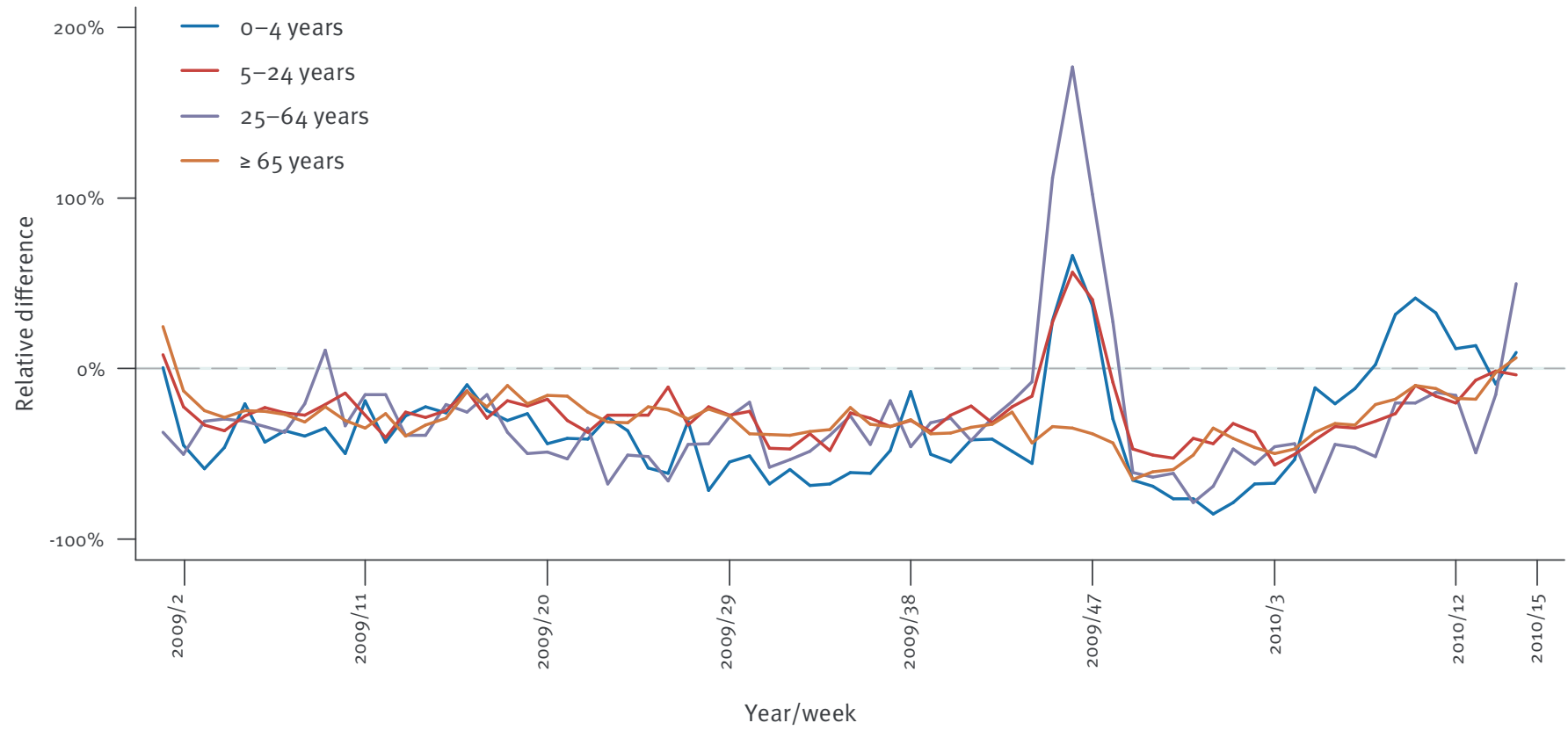

The $99 \%$ confidence interval for the prediction line was obtained from the negative binomial regression model based on pre-pandemic hospitalisation data. 
from this virus in this age group [13]. Another possible contribution to the differences between age groups and the two countries is the immunisation policy adopted against the pandemic influenza. In Finland, vaccination campaigns started with healthcare workers and risk groups before the peak in October 2009, then reached out to other target groups, such as children, and finally reached the general population around early January of 2010 [unpublished data THL]. The highest vaccination coverage was reached in 5-14-year-old children $(76 \%)$ and the lowest in adults aged $20-29(31 \%)$. In Denmark, vaccination against the pandemic influenza was offered to healthcare workers and risk groups including children aged three years or more in October 2009; the general population including healthy children were included in the vaccination programme at the end of February 2010 [14]. The differences in vaccination policies arose partly from unresolved questions regarding the effectiveness of immunisation in young children [15], but a growing body of literature supports the view that the burden of the disease was previously underestimated [16].

Our analyses by a list of ICD-10 codes previously used in the United States [6,8] and Denmark [9], revealed an increase in hospital discharges coded as influenza and viral or unspecified pneumonia, especially in children and adults. For the ARDS diagnostic group, an increase during the pandemic was observed in children and persons aged 65 and above, but due to the small numbers, these results should be interpreted with caution. The smaller numbers of hospital discharges coded as ARDS in our study as compared to the numbers found in Denmark [9] may reflect differences in clinical practice and the usage of ICD-10 codes between the two countries, which have similar population sizes (The Danish population is 5.5 million). Hospital discharges coded as bacterial pneumonia were fewer during the influenza $A\left(\mathrm{H}_{1} \mathrm{~N}_{1}\right)$ pdmog pandemic as compared to the pre-pandemic seasons in all the age groups, including children and persons aged 65 and above, which are the two groups usually most vulnerable to secondary bacterial infections during seasonal influenza waves [17]. Febrile convulsions in children were also less frequent during the influenza $A\left(\mathrm{H}_{1} \mathrm{~N}_{1}\right)$ pdmog pandemic, an observation also reported from Australia [18].

In the age-specific time series over the whole 14 -year period, we observed seasonal influenza peaks in persons aged 65 and above and in children; these two age groups also showed the largest variation in the hospitalisation rate between seasonal peaks, except for the pandemic where the absence of excess in those aged 65 and above was a striking finding. The influenza season of 2003/04 represented the second most important peak in hospitalisations in all groups (and the highest peak in people aged 65 and above) and was dominated by an influenza $A\left(\mathrm{H}_{3} \mathrm{~N}_{2}\right)$ virus of the Fujian lineage which represented a major drift in the $\mathrm{H}_{3} \mathrm{~N}_{2}$ virus causing poor match with the then available seasonal influenza vaccine [10].
Our study has several limitations. Firstly, we were unable to determine the possible impact of the increased awareness regarding influenza and its potential complications, especially among younger age groups, during the influenza $A\left(\mathrm{H}_{1} \mathrm{~N}_{1}\right)$ pdmog pandemic, a phenomenon that could affect both diagnostic activity and the threshold for hospitalisation, resulting in higher numbers of influenza and influenza-associated ICD-10 codes appearing in the hospital discharge register. An English study limited to laboratory-confirmed cases of influenza during the pandemic revealed lower hospitalisation rates than in other countries, which can possibly be explained by differences in the threshold for hospital admission; however, hospitalisation was far more common in patients with pre-existing medical conditions [19]. Influenza infection causes the exacerbation of cardiopulmonary diseases, which could also be seen as an excess in hospitalisation rates [8]. Secondly, a weakness was related to the structure of the HILMO data as compared to the Danish hospital discharge register, since only the three first ICD-10 codes from each medical record were collected in the register, whereas the Danish register provided an unlimited number of ICD-10 codes [9]. Coding for influenza infection may be noted among the later diagnoses in patients suffering from multiple illnesses. However, in a study from the United States by Simonsen et al., only the code provided in the first position was considered [6]. Finally, we were not able to use the model for continuous monitoring, as hospital discharge data is collected by HILMO only annually; data delivery at least on a monthly basis would enable timely surveillance.

Our hospitalisation data covered the whole country, minimising bias due to regional differences in the population and the healthcare structure; the same coverage was obtained in the Danish study [9]. In contrast, we used age-specific population denominators, resulting in hospitalisation rates useful for international comparisons $[6,8]$. We used hospitalisation data from a total of 14 years when building the prediction model for the pandemic, and the resulting model thus accommodates information from various types of influenza seasons, including the 2003-2004 season with its high burden of disease. Furthermore, we added weekly numbers of seasonally circulating respiratory pathogens reported to nationwide laboratory-based surveillance as covariates to the model, and we obtained a very good fit of the prediction line for pre-pandemic seasons 1996-2009, as suggested by previous studies on influenza-associated mortality $[7,20]$ and on overall influenza surveillance $[11,21]$. These covariates proved useful as we observed a second peak in hospitalisations among children aged $0-4$ years in early 2010; after comparison with the time series of individual respiratory pathogens, we suspected this age-dependant observation to be due to a higher circulation of RSV.

In conclusion, the present study showed a differential burden of influenza-associated hospitalisations during 
the influenza $A\left(\mathrm{H}_{1} \mathrm{~N}_{1}\right)$ pdmog pandemic as compared to previous seasons by age and diagnostic groups. The availability of surveillance data describing the burden of influenza on healthcare systems for all age groups is important when assessing changes in influenza dynamics in future seasons and pandemics, when evaluating immunisation priorities and recommendations for use of antiviral medications [2,15,22]. The monitoring of influenza-associated hospitalisations is an important complementary approach to the surveillance of excess in all-cause mortality and the case-based surveillance of severe cases, but the data from the monitoring needs to be timely. Integration of epidemiological and microbiological data is an important part of the modelling process, which will require calibration in future studies that should also allow for international comparisons of hospitalisation rates.

\section{References}

1. Amato-Gauci A, Zucs P, Snacken R, Ciancio B, Lopez V, Broberg $E$, et al. Surveillance trends of the 2009 influenza $A\left(\mathrm{H}_{1} \mathrm{~N}_{1}\right)$ pandemic in Europe. Euro Surveill. 2011;16(26):pii=19903. Available from: http://www.eurosurveillance.org/ViewArticle. aspx?Articleld=19903

2. Lyytikainen O, Kuusi M, Snellman M, Virtanen M, Eskola J, Ronkko E, et al. Surveillance of influenza in Finland during the 2009 pandemic, 10 May 2009 to 8 March 2010. Euro Surveill. 2011;16(27):pii=19908. Available from: http://www. eurosurveillance.org/ViewArticle.aspx?Articleld =19908

3. Centers for Disease Control and Prevention (CDC). Surveillance for laboratory-confirmed, influenza-associated hospitalizations--Colorado, 2004-05 influenza season. MMWR Morb Mortal Wkly Rep. 2005;54(21):535-7.

4. The European Mortality Monitoring Project. [Accessed 20 Sep 2012]. Available from: http://www.euromomo.eu/

5. Mazick A, Gergonne B, Wuillaume F, Danis K, Vantarakis A, Uphoff $\mathrm{H}$, et al. Higher all-cause mortality in children during autumn 2009 compared with the three previous years: pooled results from eight European countries. Euro Surveill. 2010;15(5):pii=19480. Available from: http://www. eurosurveillance.org/ViewArticle.aspx?Articleld=19480

6. Simonsen L, Fukuda K, Schonberger LB, Cox NJ. The impact of influenza epidemics on hospitalizations. J Infect Dis. 2000;181(3):831-7.

7. Thompson WW, Moore MR, Weintraub E, Cheng PY, Jin X, Bridges CB, et al. Estimating influenza-associated deaths in the United States. Am J Public Health. 2009;99 Suppl 2:S225-30.

8. Thompson WW, Shay DK, Weintraub E, Brammer L, Bridges CB, Cox NJ, et al. Influenza-associated hospitalizations in the United States. JAMA. 2004;292(11):1333-40.

9. Widgren K, Nielsen J, Mølbak K. Registry-based surveillance of influenza-associated hospitalisations during the 2009 influenza pandemic in Denmark: the hidden burden on the young. PLoS One. 2010;5(11):e13939.

10. Hulkko T, Lyytikäinen O, Kuusi M, Seppälä S, Ruutu P, editors. Infectious Diseases in Finland 1995-2009. Helsinki: National Institute for Health and Welfare; 2010. Available from: http://www.thl.fi/thl-client/pdfs/ d6d63c66-9690-4f4d-9ee1-319bb5648eaf

11. Thompson WW, Comanor L, Shay DK. Epidemiology of seasonal influenza: use of surveillance data and statistical models to estimate the burden of disease. J Infect Dis. 2006;194 Suppl 2:S82-91.

12. Simonsen L, Reichert TA, Viboud C, Blackwelder WC, Taylor RJ, Miller MA. Impact of influenza vaccination on seasonal mortality in the US elderly population. Arch Intern Med. 2005;165(3):265-72.

13. Ikonen N, Strengell M, Kinnunen L, Osterlund P, Pirhonen J, Broman $M$, et al. High frequency of cross-reacting antibodies against 2009 pandemic influenza $A\left(\mathrm{H}_{1} \mathrm{~N}_{1}\right)$ virus among the elderly in Finland. Euro Surveill. 2010;15(5):pii=19478. Available from: http://www.eurosurveillance.org/ViewArticle. aspx?Articleld=19478

14. Statens Serum Institut (SSI). Vaccination mod influenza A $\left(\mathrm{H}_{1} \mathrm{~N}_{1}\right) v \mathrm{i}$ almen praksis. [Vaccination against influenza $\mathrm{A}\left(\mathrm{H}_{1} \mathrm{~N}_{1}\right)$ v]. SSI: Copenhagen; 2009. Dutch. Available from: http://www. ssi.dk/Aktuelt/Nyhedsbreve/EPI-NYT/ /media/Indhold/DK\%20 -\%20dansk/Aktuelt/Nyhedsbreve/EPI-NYT/2009/2009\%20PDF/ EPI-NYT\%20-\%202009\%20-\%20uge\%2041.ashx

15. Heikkinen T, Heinonen S. Effectiveness and safety of influenza vaccination in children: European perspective. Vaccine. 2011;29(43):7529-34.

16. Nair H, Brooks WA, Katz M, Roca A, Berkley JA, Madhi SA, et al. Global burden of respiratory infections due to seasonal influenza in young children: a systematic review and metaanalysis. Lancet. 2011;378(9807):1917-30.

17. Rothberg MB, Haessler SD, Brown RB. Complications of viral influenza. Am J Med. 2008;121(4):258-64.

18. Polkinghorne BG, Muscatello DJ, Macintyre CR, Lawrence GL, Middleton PM, Torvaldsen S. Relationship between the population incidence of febrile convulsions in young children in Sydney, Australia and seasonal epidemics of influenza and respiratory syncytial virus, 2003-2010: a time series analysis. BMC Infect Dis. 2011;11:291.

19. Campbell CN, Mytton OT, McLean EM, Rutter PD, Pebody RG, Sachedina N, et al. Hospitalization in two waves of pandemic influenza $A\left(\mathrm{H}_{1} \mathrm{~N}_{1}\right)$ in England. Epidemiol Infect. 2011;139(10):1560-9.

20. Centers for Disease Control and Prevention (CDC). Estimates of deaths associated with seasonal influenza -.- United States, 1976-2007. MMWR Morb Mortal Wkly Rep. 2010;59(33):1057-62.

21. Monto AS, Comanor L, Shay DK, Thompson WW. Epidemiology of pandemic influenza: use of surveillance and modeling for pandemic preparedness. J Infect Dis. 2006;194 Suppl 2:S92-7.

22. Salo H, Kilpi T, Sintonen H, Linna M, Peltola V, Heikkinen T. Cost-effectiveness of influenza vaccination of healthy children. Vaccine. 2006;24(23):4934-41. 